\title{
A Simple and Advantageous Synthesis of the Privileged 1,4-Benzodiazepine Nucleus
}

\author{
Neetu Jain and Dharma Kishore \\ Department of Chemistry, Banasthali University, Banasthali, Rajasthan 304022, India \\ Correspondence should be addressed to Neetu Jain; to.neetu@yahoo.com
}

Received 30 April 2014; Revised 5 July 2014; Accepted 11 July 2014; Published 11 August 2014

Academic Editor: Hideto Miyabe

Copyright (C) 2014 N. Jain and D. Kishore. This is an open access article distributed under the Creative Commons Attribution License, which permits unrestricted use, distribution, and reproduction in any medium, provided the original work is properly cited.

A novel domino approach has been described for an easy access of the privileged nucleus of 5-carbomethoxy substituted 1,4-benzodiazepin-2-ones $\mathbf{4}(\mathbf{a}-\mathbf{i})$ from an in situ methanolic hydrolysis of an incipient species formed from the interaction of 1-chloroacetylisatin 2(a-i), hexamethyldisilazane, and n-butyl lithium. The reaction is believed to take place through a consecutive series of intramolecular reactions in a cascade to first generate a highly reactive carbene intermediate $\mathbf{3}(\mathbf{a}-\mathbf{i})$ from 1-chloroacetylisatin and n-butyl lithium which is simultaneously trapped by hexamethyldisilazane before undergoing its in situ hydrolysis with methanol to initiate its concomitant cyclocondensation to produce $4(\mathbf{a}-\mathbf{i})$ in high yield and purity.

\section{Introduction}

Exploration of synthetic processes that lead to the development of small molecules of medicinal interest by telescoping the multicomponent operations into a single step or resorting to a process such as domino reactions is a rapidly emerging subject in medicinal chemistry. Ever since Koch et al. [1] carried out a quantitative analysis of physiologically active natural product scaffolds and showed that ones with two or three rings were most often found in bioactive natural products, the interest on various facets of the chemistry of small molecules has expanded exponentially thereafter. Benzodiazepines and their analogues have been recognized recently to belong to the class of privileged heterocyclic structures, [2-5] by virtue of their ability to form ligands to a number of functionally and structurally discrete biological receptors [6-13]. This property stimulated chemists to utilize their potential in the design and development of molecular probes for biological evaluations. Ubiquitous presence of this nucleus in the psychopharmacologically active agents and in molecules active against HIV infection, for example, TIBO (1) [14-17] and FDA approved dipyrido diazepine analogue nevirapine (2) [18-24] in Figure 1 provided an impetus for an enormous research effort to be directed towards the development of their structural analogues of medicinal importance $[25,26]$.

\section{Results and Discussion}

This communication reports the application of a novel domino process for an easy access of the privileged nucleus of 5-carbomethoxy substituted 1,4-benzodiazepin-2-ones $4(\mathbf{a}-\mathbf{i})$ from the ring expansion of 1-chloroacetylisatins 2(a-i), initiated by hexamethyldisilazane under the influence of n-butyl lithium. N-Butyl lithium formed an obvious choice since it has been used as a catalyst in amination of active alkyl halides with hexamethyldisilazane. Amination of 1chloroacetylisatin (2) formed the key step in allowing it to undergo ring expansion to give 4. Ogata and Matsumoto's [27] original procedure which employed Delepine reaction in the amination of $\mathbf{2}$ with methanolic solution of hexamine produced 4 in low yield. This called out to revisit this reaction to augment the scope of this reaction in view of the yield of this product.

It is believed that Delepine reaction proceeded with the formation of the hexaminium ion. We surmise that it was the bulky nature of hexamine which hindered its formation 


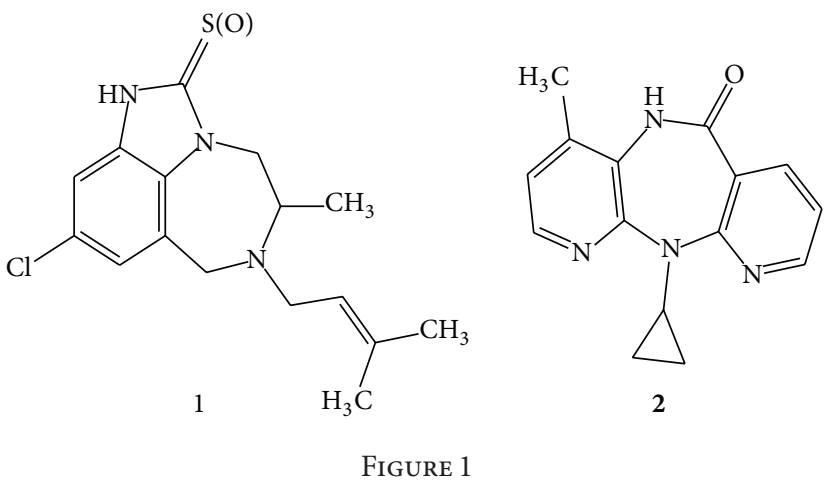

from 2. We assumed that this problem could possibly be circumvented by carrying out the amination of $\mathbf{2}$ with less bulkier agents. In consideration of the potential of hexamethyldisilazane [28] in amination reaction, in our initial attempt, we replaced hexamine with this reagent. However, contrary to our expectation, 2 resisted its reaction with this reagent and caused it to be recovered unchanged from the reaction mixture. A search for possible use of a catalyst in this reaction revealed that $n$-butyl lithium has been used in aminations employing hexamethyldisilazane. This provided optimism for this reaction too, to succeed with the use of this catalyst. This expectation turned into a reality in all the runs using a wide variety of substituted 1-chloroacetylisatin derivatives to produce 4 in an exceptionally high yield and purity (Table 1).

We suggest that this reaction proceeds with the base catalysed dehydrochlorination of $\mathbf{2}$ to generate an acyl carbene intermediate 3 which is subsequently trapped by hexamethyldisilazane. The relatively small size of carbene precludes the steric factor in the reaction with hexamethyldisilazane. The hydrolysis of bis(trimethylsilyl) group from this with methanol sets the stage for it, to undergo ring expansion to give 4 .

In view of the extremely weak nucleophilic character of isatinylamide nitrogen of $\mathbf{3}$, the possibility of the rearrangement of the acyl carbene intermediate had to be ruled out. (No rearranged product was, however, traceable from the reaction mixture.)

As the carbene was not likely to be trapped by the tertiary amine (hexamine) its reaction with hexamine was not examined.

\section{Experiment}

All the melting points were taken in open capillaries and are uncorrected. The purity of all the compounds were checked by TLC using the solvent systems (benzene:methanol, $9: 1 \mathrm{v} / \mathrm{v}$ ) and silica gel $G$ as adsorbent. IR spectra were recorded on Shimadzu FTIR-8400 infrared spectrometer using $\mathrm{KBr},{ }^{1} \mathrm{H}$ NMR were recorded on Bruker AC $300 \mathrm{~F}$ in $\mathrm{CDCl}_{3}+\mathrm{DMSO}_{6}(2: 1 \mathrm{v} / \mathrm{v}$, TMS as internal reference and chemical shifts expressed in $\delta$ ppm), and mass spectra were recorded on Jeol-JMS-D-D-300 mass spectrometer. Reagents, 5-fluoro-, 5-chloro-, 5-bromo-, 5-iodo-, 5-methyl-, 5-methoxy-, 5-nitro-, and 5,7-dimethylisatins were procured from commercial sources and used as such in the reaction without further purifications (see Scheme 1).

3.1. General Methods for the Preparation of $\mathbf{2}(\mathbf{a}-\mathbf{i})$ from $\mathbf{1}(\mathbf{a}-\mathbf{i})$. 5-Fluoroisatin (1b, $0.068 \mathrm{~mol})$ was vigorously refluxed with chloroacetyl chloride $(0.090 \mathrm{~mol})$ for $7 \mathrm{~h}$. and the mixture was cooled overnight at $0-5^{\circ} \mathrm{C}$. The crude product which settled was filtered, washed with $20 \mathrm{~mL}$ of ether, air-dried, and then recrystallised from ethyl acetate to give $\mathbf{2 b}$, yield: $88 \%$, m.p. $165-166^{\circ} \mathrm{C}$. Other compounds 2 (a, c-i) were prepared from $\mathbf{1}(\mathbf{a}, \mathbf{c}-\mathbf{i})$ using this procedure.

3.2. General Methods for the Preparation of $4(\mathbf{a}-\mathbf{i})$ from $2(\mathbf{a}-$ i). 5-Fluoro-1-chloroacetylisatin (2b,0.01 mol) was dissolved in dry THF $(20 \mathrm{~mL})$ and to this solution n-butyl lithium $(0.01 \mathrm{~mol})$ and hexamethyldisilazane $(0.01 \mathrm{~mol})$ were added. The reaction mixture was magnetically stirred for $2 \mathrm{~h}$ at room temperature. The progress of reaction was checked by TLC. Methanol $(20 \mathrm{~mL})$ was added to the reaction mass and the mixture was refluxed for $5 \mathrm{~h}$. It was then poured on crushed ice, filtered, air-dried, and recrystallised from methanol to give $\mathbf{4 b}$, yield: $87 \%$, m.p. $198-200^{\circ} \mathrm{C}$. Other compounds $4(\mathbf{a}$, $\mathbf{c}-\mathbf{i})$ were prepared from $2(\mathbf{a}, \mathbf{c}-\mathbf{i})$ using the same procedure.

\section{Conclusion}

In summary, a high yielding n-butyl lithium catalysed one-pot domino process has been developed to the facile access of the privileged nucleus of methyl-1,3-dihydro- $2 \mathrm{H}$ 1,4-benzodiazepin-2-one-5-carboxylates $\mathbf{4}(\mathbf{a}-\mathbf{i})$ at ambient temperature from the ring expansion of the corresponding 1chloroacetylisatins $2(\mathbf{a}-\mathbf{i})$ under the influence of hexamethyldisilazane.

\section{Conflict of Interests}

The authors declare that there is no conflict of interests regarding the publication of this paper. 


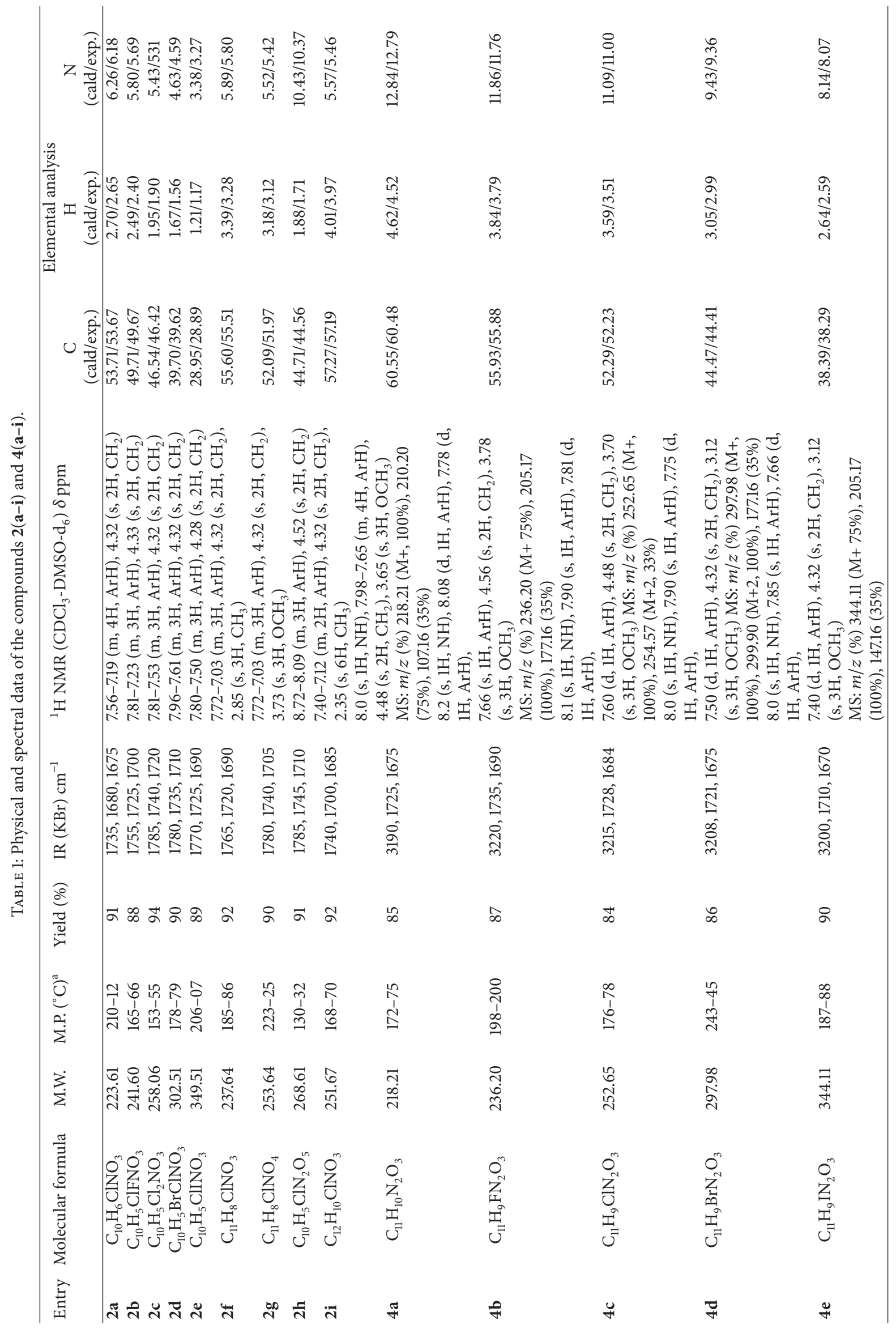




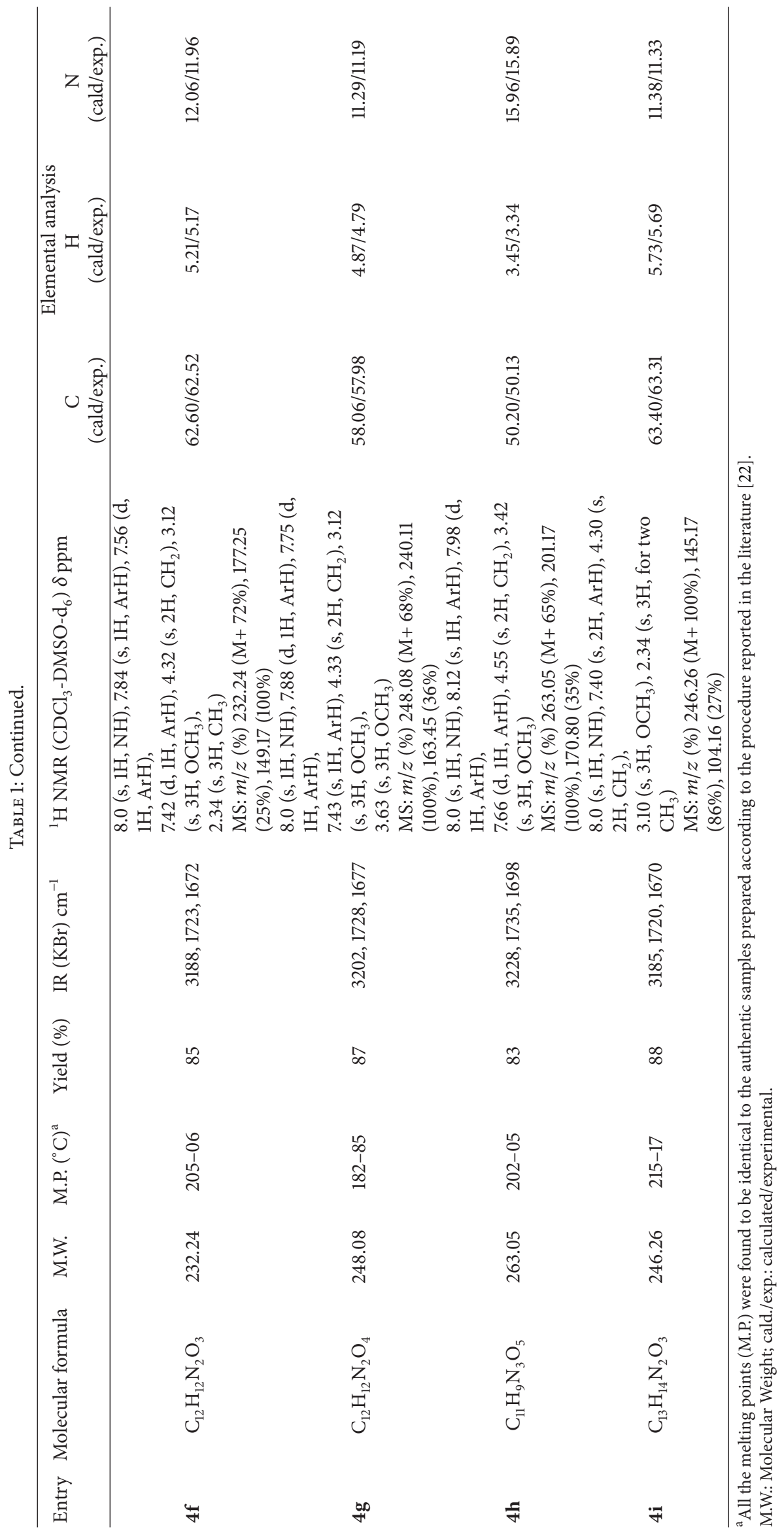




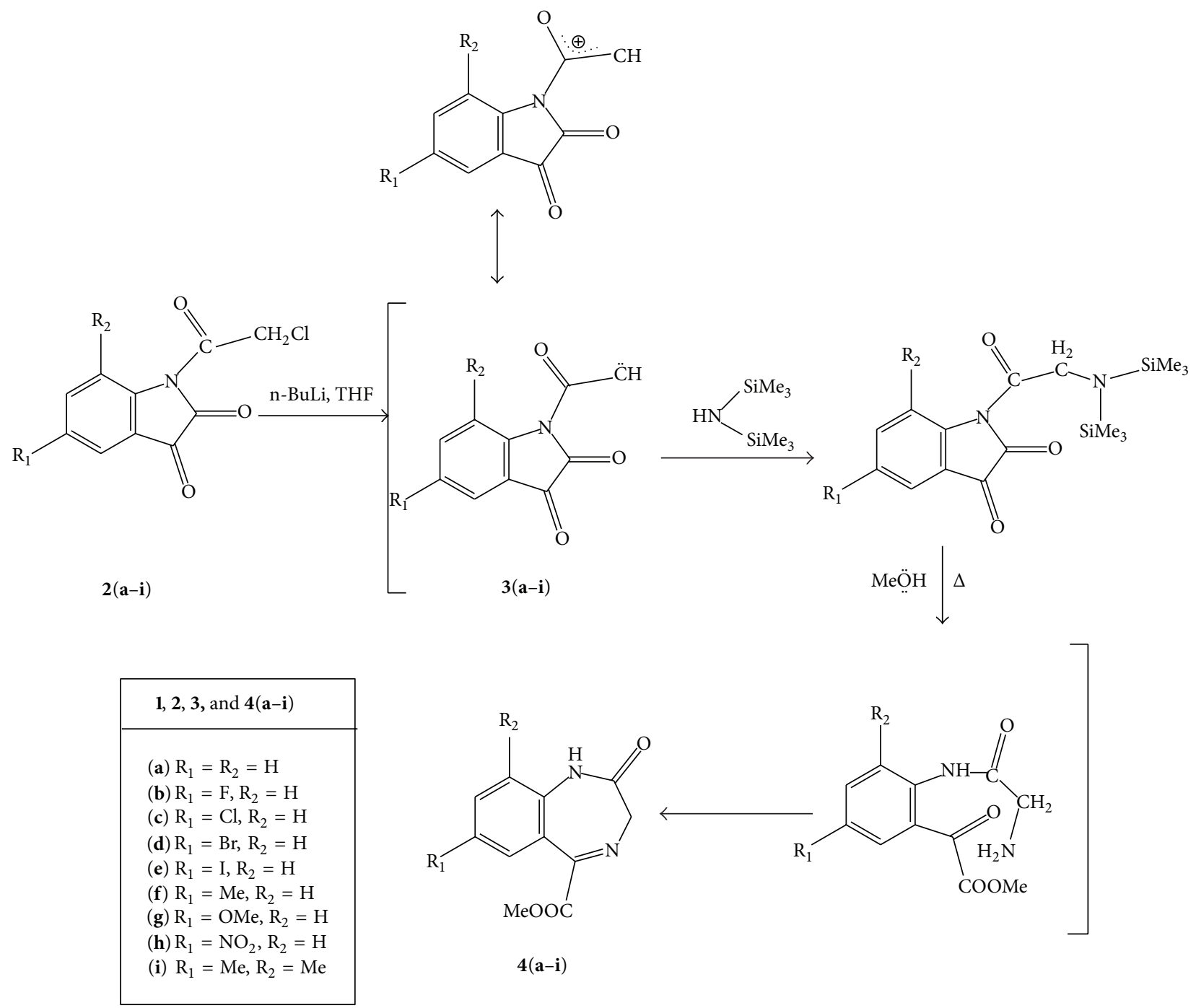

SCHEme 1: Schematic presentation of the synthesis of the compounds.

\section{Acknowledgments}

The authors are grateful to the Director of CDRI, Lucknow, India, for providing the spectral data of the compounds and to the Department of Science and Technology, DST, New Delhi, India, for providing the financial assistance to "Banasthali Centre for Education and Research in Basic Sciences," under their CURIE (Consolidation of University Research for Innovation and Excellence in Women Universities) programme.

\section{References}

[1] M. A. Koch, A. Schuffenhauer, M. Scheck et al., "Charting biologically relevant chemical space: a structural classification of natural products (SCONP)," Proceedings of the National Academy of Sciences of the United States of America, vol. 102, no. 48, pp. 17272-17277, 2005.

[2] W. Nawroca, B. Sztuba, A. Opolski, J. Wietrzk, M. W. Kowalska, and T. Glowiak, "Synthesis and antiproliferative activity in vitro of novel 1,5-benzodiazepines. Part II," Archive der PharmaziePharmaceutical and Medicinal Chemistry, vol. 334, no. 1, pp. 310, 2000.

[3] B. E. Evans, K. E. Rittle, M. G. Bock et al., "Methods for drug discovery: development of potent, selective, orally effective cholecystokinin antagonists," Journal of Medicinal Chemistry, vol. 31, no. 12, pp. 2235-2246, 1988.

[4] R. Yarchoan, H. Mitsuya, R. V. Thomas et al., "In vivo activity against HIV and favorable toxicity profile of $2^{\prime}, 3^{\prime}$ dideoxyinosine," Science, vol. 245, no. 4916, pp. 412-415, 1989.

[5] J. R. Lokensgard, C. C. Chao, G. Gekker, S. Hu, and P. K. Peterson, "Benzodiazepines, glia, and HIV-1 neuropathogenesis," Molecular Neurobiology, vol. 18, no. 1, pp. 23-33, 1998.

[6] J. Poupaert, P. Carato, E. Colacino, and S. Yous, "2(3H)benzoxazolone and bioisosters as "privileged scaffold" in the design of pharmacological probes," Current Medicinal Chemistry, vol. 12, no. 7, pp. 877-885, 2005.

[7] D. J. Triggle, "1,4-dihydropyridines as calcium channel ligands and privileged structures," Cellular and Molecular Neurobiology, vol. 23, no. 3, pp. 293-303, 2003. 
[8] R. W. DeSimone, K. S. Currie, S. A. Mitchell, J. W. Darrow, and D. A. Pippin, "Privileged structures: applications in drug discovery," Combinatorial Chemistry and High Throughput Screening, vol. 7, no. 5, pp. 473-493, 2004.

[9] A. A. Patchett and R. P. Nargund, "Chapter 26. Privileged structures: an update," Annual Reports in Medicinal Chemistry, vol. 35, pp. 289-298, 2000.

[10] J. Yang, Q. Dang, J. Liu, Z. Wei, J. Wu, and X. Bai, "Preparation of a fully substituted purine library," Journal of Combinatorial Chemistry, vol. 7, no. 3, pp. 474-482, 2005.

[11] J. Liu, Q. Dang, Z. Wei, H. Zhang, and X. Bai, "Parallel solutionphase synthesis of a 2,6,8,9-tetrasubstituted purine library via a sulfur intermediate," Journal of Combinatorial Chemistry, vol. 7, no. 4, pp. 627-636, 2005.

[12] Q. Dang and J. E. Gomez-Galeno, "An efficient synthesis of pyrrolo[2,3-d]pyrimidines via inverse electron demand Diels-Alder reactions of 2-amino-4-cyanopyrroles with 1,3,5triazines," Journal of Organic Chemistry, vol. 67, no. 24, pp. 8703-8705, 2002.

[13] P. Bhuyan, R. C. Boruah, and J. S. Sandhu, "Studies on uracils. 10. A facile one-pot synthesis of pyrido[2,3-d]- and pyrazolo[3,4d]pyrimidines," Journal of Organic Chemistry, vol. 55, no. 2, pp. 568-571, 1990.

[14] R. H. Smith Jr., W. L. Jorgen, J. Tirado-Rives et al., "Prediction of binding affinities for TIBO inhibitors of HIV-1 reverse transcriptase using Monte Carlo simulations in a linear response method," Journal of Medicinal Chemistry, vol. 41, no. 26, pp. 5272-5286, 1998.

[15] B. A. Roberte, K. Andries, J. Desayter et al., "Potent and selective inhibition of HIV-1 replication in vitro by a novel series of TIBO derivatives," Nature, vol. 343, no. 6257, pp. 470-474, 1990.

[16] H. J. Breslin, M. J. Kukla, T. Kromis et al., "Synthesis and antiHIV activity of 1,3,4,5-tetrahydro-2H-1,4- benzodiazepin-2one (TBO) derivatives. Truncated 4,5,6,7-tetrahydro-5- methylimidazo[4,5,1-jk][1,4]benzodiazepin-2(1H)-ones (TIBO) analogues," Bioorganic and Medicinal Chemistry, vol. 7, no. 11, pp. 2427-2436, 1999.

[17] W. Ho, M. J. Kukla, H. J. Breslin et al., "Synthesis and antiHIV-1 activity of 4,5,6,7-tetrahydro-5-methylimidazo-[4,5,1jk] $[1,4]$ benzodiazepin-2(1H)-one (TIBO) derivatives. 4," Journal of Medicinal Chemistry, vol. 38, no. 5, pp. 794-802, 1995.

[18] B. D. Puodziunaite, R. Janciene, L. Kosychova, and Z. Stumbreviciute, "On the synthetic way to novel peri-annelated imidazo[1,5]benzodiazepinones as the potent non-nucleoside reverse transcriptase inhibitors," Arkivoc, vol. 2000, no. 4, pp. 512-522, 2000.

[19] M. D. Braccio, G. Grossi, G. Roma, L. Vargiu, M. Mura, and M. E. Marongiu, "1,5-Benzodiazepines. Part XII. Synthesis and biological evaluation of tricyclic and tetracyclic 1,5benzodiazepine derivatives as nevirapine analogues," European Journal of Medicinal Chemistry, vol. 36, no. 11-12, pp. 935-949, 2001.

[20] A. Kamal, M. V. Rao, N. Laxman, G. Ramesh, and G. S. Reddy, "Recent developments in the design, synthesis and structure-activity relationship studies of pyrrolo[2,1c] $[1,4]$ benzodiazepines as DNA-interactive antitumour antibiotics," Current Medicinal Chemistry-Anti-Cancer Agents, vol. 2, no. 2, pp. 215-254, 2002.

[21] P. Sharma, B. Vashistha, R. Tygai et al., "Application of microwave induced Delepine reaction to the facile one pot synthesis of 7-substituted 1,3-dihydro-2H-[1,4]-benzodiazepin2-one-5-methyl carboxylates from the corresponding 1chloroacetylisatins," International Journal of Chemical Sciences, vol. 8, no. 1, 2010.

[22] A. Singh, R. Sirohi, S. Shastri, and D. Kishore, "A facile one-pot synthesis of 7-substituted-5-methoxycarbonyl-1H-2, 3-dihydro1, 4-benzodiazepin-2-ones from 5 -substituted- $N$-chloroacetyl isatins," Indian Journal of Chemistry B, vol. 42B, no. 12, pp. 31243127, 2003.

[23] P. D. Popp, "The chemistry of isatin," in Advances in Heterocyclic Chemistry, vol. 18, pp. 1-58, 1975.

[24] M. Pal, N. K. Sharma, Priyanka, and K. K. Jha, "Synthetic and biological multiplicity of isatin: a review," Journal of Advanced Scientific Research, vol. 2, no. 2, pp. 35-44, 2011.

[25] N. Blazevic, D. Kolbah, B. Belin, V. Sunjic, and F. Kajfez, "Hexamethylenetetramine, "A versatile reagent in organic synthesis",' Synthesis, pp. 167-176, 1979.

[26] B. Rigoa, P. Caulieza, D. Fasseurb, and D. Couturierb, "Reaction of hexamethyldisilazane with diacylhydrazines: an easy 1,3,4oxadiazole synthesis," Synthetic Communications, vol. 16, no. 13, pp. 1665-1669, 1986.

[27] M. Ogata and H. Matsumoto, "A convenient synthesis of 5-substituted 1,3-dihydro-2H-1,4-benzodiazepine-2-ones," Chemistry and Industry, p. 1067, 1976.

[28] H. Fujishima, H. Takeshita, S. Suzuki, M. Toyota, and M. Ihara, "Hexamethyldisilazanes mediated one-pot intramolecular Michael addition-olefination reactions leading to ejvoolefinated bicyclo[6.4.0]dodecanes," Journal of the Chemical Society, Perkin Transactions 1, no. 18, pp. 2609-2616, 1999. 

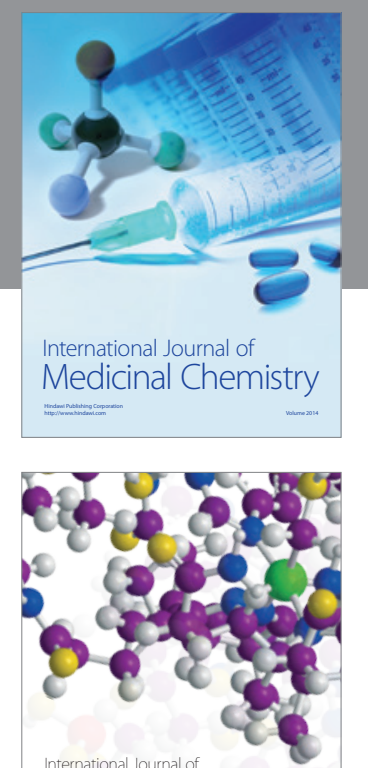

\section{Carbohydrate} Chemistry

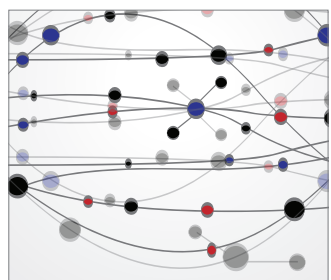

The Scientific World Journal
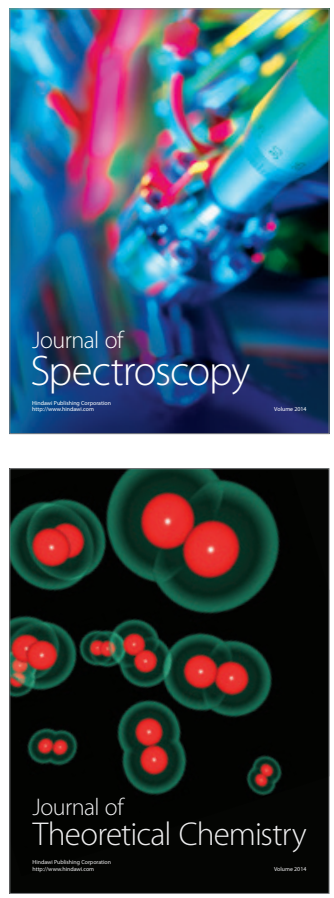
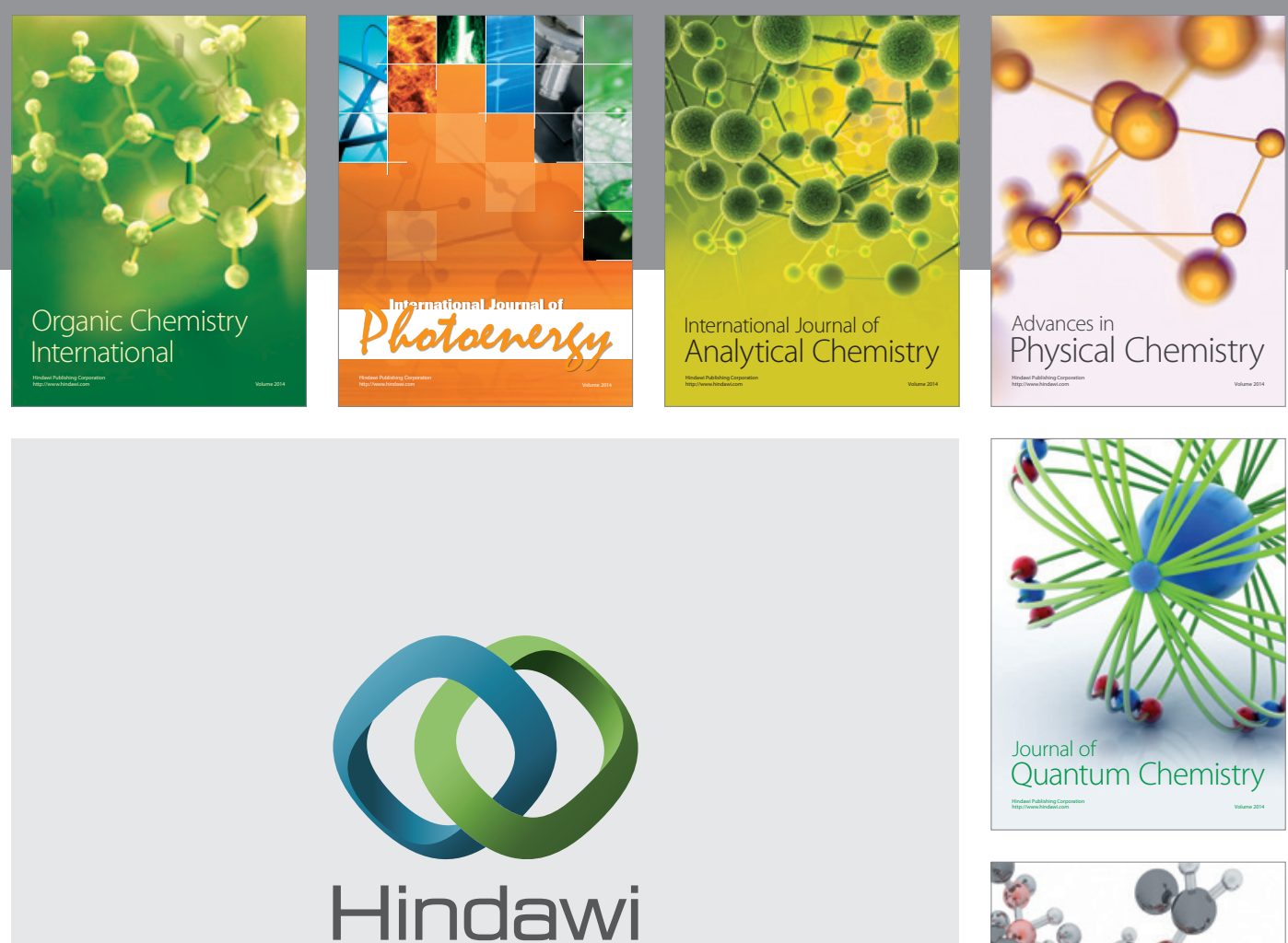

Submit your manuscripts at

http://www.hindawi.com

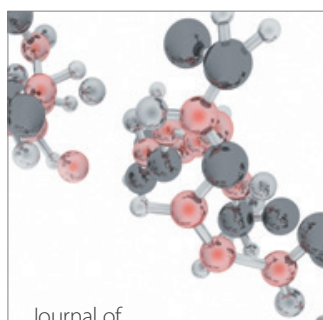

Analytical Methods

in Chemistry

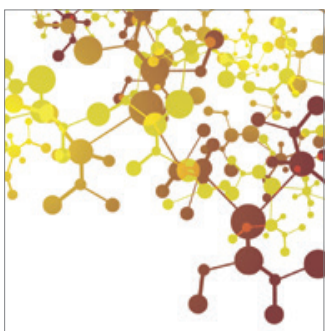

Journal of

Applied Chemistry

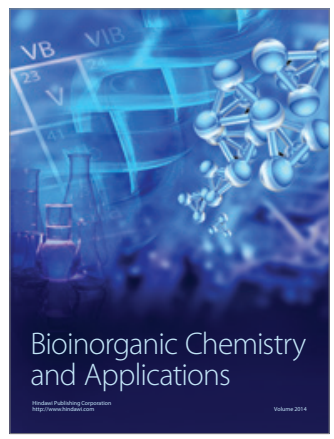

Inorganic Chemistry
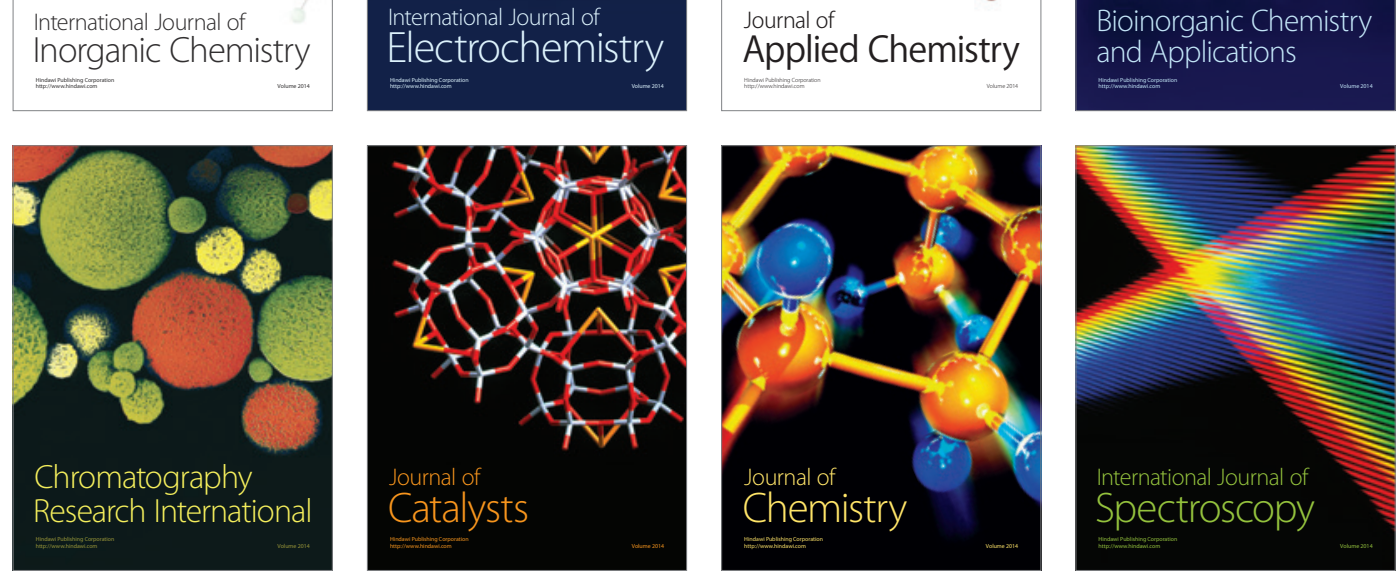